\title{
Just Noticeable Difference: The Marketplace EXPERIENCE OF GENERAL MOTORS
}

\author{
Thomas L. Powers \\ Graduate School of Management \\ The University of Alabama at Birmingham \\ Birmingham, Alabama
}

In mature markets, consumer perceptions of products are vitally important for the firm involved. Products are typically similar, and care must be taken to maintain enough differences between them to insure that the marketplace will see them as discrete offerings. Recently, General Motors encountered problems in differentiating its products between market segments [23], a situation which resulted in lost market share, much to the concern of GM shareholders and management [6]. Many of these problems have been attributed to GM's management, which has been viewed as carrying out an ill-conceived strategy differing from past practices [8].

This paper examines General Motor's problem with similarly appearing products through the use of the "just noticeable difference" concept (j.n.d.) ([1], p. 140), which can be used to explain the requisite level of perceived difference between products. Several factors can affect this required level of difference, including consumers' previous product perceptions, changing demographics, and the number of products in the market.

For a firm such as General Motors, the level of product differences could remain relatively constant from year to year. However, due to the factors noted above, consumers' level of perceived difference may be reduced. Additional competing products in the market can also result in limiting the number of distinct product positions [21]. By understanding these relationships, which are discussed in this paper, managers can anticipate and act on market developments that require a change in the level of differentiation between products.

\section{The General Motors Experience}

General Motors represents a very real and current example of the problem of differentiating products. The impact of products that are seen as similar by the marketplace has been dramatic. In 1987, GM's market share dropped to $37 \%$ of the market nationwide, and to less than $25 \%$ in the bellweather state of California [13]. The $37 \%$ share contrasts sharply with a market share of more than $50 \%$ that prevailed for most of the post-World War II period. A brief discussion of the history of General Motors' product line helps explain how GM's problem came about and

Journal of Business Strategies, Volume 5, Number 2 (Fall 1988) 
provides some insight into how other firms can anticipate and measure the actual and required perceived differences between products.

\section{Structuring the General Motors' Product Line 1897-1919}

General Motors began not as a monolithic manufacturer of automobiles as it is seen today, but as a collection of different automobile companies. Oldsmobile, the oldest firm to become a part of General Motors, was established in 1897 and by 1904 had produced 12,500 cars $([12]$, p. 16). The Cadillac Automobile Company and the Buick Manufacturing Company both were organized in 1902 with Buick providing the base for the modern General Motors. By 1907 Buick had become the second largest manufacturer of automobiles in the country, and in 1908 William C. Durant incorporated General Motors, which was to include Buick, Oldsmobile, Oakland, and Cadillac by 1909. Chevrolet was added in 1918, and by 1920 more than 30 companies became a part of the General Motors holding company.

With the multiple product lines, Durant created a high level of market segmentation, i.e., the viewing of a heterogeneous market as a combination of a number of smaller homogeneous markets in response to differing product preferences among market segments [20]. He believed that the future would belong to the automobile company that produced a line of motorcars ranging from light, inexpensive cars to large, expensive vehicles which would appeal to several market segments ([9], p. 235). In addition, GM utilized product differentiation, a process which creates distinct images for a firm's products vis-a-vis their competition [20]. For example, the Chevrolet automobile and marketing effort were designed to appeal to a cost-conscious market segment, and at the same time the automobile was differentiated from its competition by its distinct image and product features ([12], p. 32).

The combination of the dual strategies of market segmentation and product differentiation resulted in several GM product lines which dearly appealed to distinct customer groups, and which in many cases were seen as superior to their competitors. During this time period, these products were different by definition since they were brought into GM as products of several different manufacturers. Independent production processes typically were maintained for several years after the acquired firms became part of General Motors. This led logically to a segmentation strategy which was developed fully a short time later.

\section{Market Segmentation 1920-1940}

During this period General Motors undertook a strategy which was one of the first examples of market segmentation on a large scale. Its goal was to find "the best car for every purse and purpose" ([12], p. 36). Chevrolet continued to be positioned as an "economy" or "entry level" automobile and was marketed with emphasis on its attributes of price, economy and value. Its many competitors within the "economy" segment included Ford and Plymouth, which today, in the context of American manufacturers, still represent the lower-priced models. Plymouth's advertising of the period encouraged buyers to examine all three "economy cars" ([22], pp. 108-09); recent 
Chrysler Corporation advertising also has followed this theme. Recently, Chevrolet has tried to re-emphasize the youthful and value image with the "Heartbeat of America" campaign that features models typically sought by entry-level buyers [18].

Pontiac, was developed as a spinoff of the Oakland automobile line to fill the market gap between the Chevrolet and the premium lines. It was positioned as an economical, low-priced car, though it was "sporty" and somewhat more upscale than a Chevrolet of the time. Pontiac today is the only one of the GM lines that has maintained its historic market position. Not surprisingly, the Pontiac strategy has met with a high level of success, with Pontiac's relative sales out-performing the other GM divisions [7].

Oldsmobile was positioned as a car for the successful person, although it was more conservative than other models; it was to serve as a restrained display of one's success in the world. This was a major repositioning of this product line, since Olds originally was famous as the first mass-produced, low priced car $([9]$, p. 52). This division currently is suffering from the positioning problem that also has affected GM in general [15]. Products of the Buick Motor Division were targeted towards those who had achieved success and were interested in making a public statement to that effect. Ironically, Buick, on which GM was founded, today has lost its market identity perhaps more than any other GM line and has been considered for elimination [5]. The Cadillac Motor Division represented the pinnacle of the GM line and was a worthy statement of the success of the individual owning one of these automobiles. Today, Cadillac has not been successful in competing with European automobiles for this segment of the market [16].

General Motors was very aggressive during this period (1920-1940), attempting to develop new products from existing lines for every market niche. New products added included the LaSalle, which was a spinoff of Cadillac. Oldsmobile developed the Viking, and Buick had the Marquette automobile ([12], p. 46). Many of these products did not survive; however, their development provides firm evidence of General Motors' desire to seek out every possible market segment.

Promotion also reinforced General Motors' segmentation strategy. Chevrolet developed the American Soap Box Derby to identify their product with young boys who soon would become entry-level buyers. Even components such as engines were developed to reinforce the images of the various product lines during this period. Cadillac offered V-16 engines which epitomized power and status, thus strengthening their appeal to the prestige segment of the market. Chevrolet had a "Blue Flame Six" that emphasized performance within a simple, economical design, making an appeal to the economy or value-conscious segment. Pontiac offered an "Economy Straight Eight" which fell between the two ends of the market spectrum and appealed to this middle segment ([12], pp. 58-63).

One must be aware that GM's products during this period were indeed different. They consisted of different components, many times were built in different plants, and were of varying lengths, weights, and designs. Each product line also offered a. 
number of different models to appeal to submarkets. For example, in 1941 Buick had 26 body styles in five different series ([12], p. 102).

\section{Fewer Product Differences 1946-1969}

After World War II General Motors increasingly created economies of scale with common components across division lines; this was the fruition of the original concept of Durant, who had envisioned a coast-to-coast system of component and assembly plants ([9], p. 235). Differences in sheetmetal, front and rear treatments, and minor trim items were used to differentiate the various lines. Eventually the GM product lines included common engines, transmissions, and other major components. This commonality was partially due to the maturation of designs, with some components, such as overhead valve V-8 engines and automatic transmissions, reaching a near state-of-the-art for the period. Body designs, although sharing common componentry, emphasized differing themes.

The previously developed brand images and the limited number of radically different products undoubtedly reinforced differences between their lines. The success and dominance of GM in the marketplace at the time was unquestioned. Although the GM products were similar (actually just as much as they are today), the marketplace viewed those products in the context of the brand images that had been developed earlier.

\section{New Markets and New Competition 1970-Present}

During this period, General Motors saw many environmental changes that impacted its operations. In the mid to late 1960 's, market emphasis had been placed on performance. However, this emphasis was short-lived - the 1970's saw two energy crises, a corresponding increase in consumer interest in economy, increased insurance premiums for owners of high performance models, and new regulations on safety and emission controls. These factors in combination caused the company to reduce costs by emphasizing more common designs and components, while maintaining its efforts to differentiate product lines by style and image.

The 1970's also saw a major market development that changed General Motors' ability to differentiate its product lines. Import sales comprised five percent of the total market in 1958 ([17], p. 33); during this period, however, they became a major force in the marketplace. By 1968 import sales had reached $10 \%$ of the total market ([17], p. 84). Despite this, General Motors continued to vigorously pursue its basic segmentation strategy unchanged. This included a reluctance to pursue vigorously the small-car market, which represented not only a large market segment, but also many first-time buyers who were building brand allegiances that would remain for many years. By 1975 imports held $18 \%$ of the market, and by $1980,27 \%$ ([17], pp. 34-35). 


\section{The New Market and the Old Strategy}

Why doesn't the brand perception strategy that worked so well in the past work today? Three factors have caused the relative differences between GM products and the market position of each of them to become diminished.

\section{Increases in the Number of Total Product Offerings}

First, the total number of products in the marketplace has caused a decrease in the relative perceived differences in General Motors cars. While General Motors has continued to differentiate its products as it did in the 1960's, the total number of products in the marketplace has increased, making the relative differences between GM products seem smaller to the average consumer. Prior to the influx of imports, General Motors had almost $50 \%$ of the products on the market. General Motors had five car lines, Ford had three (excluding the short-lived Edsel), and Chrysler had three (after the demise of the DeSoto).

After the decade of the 1970's, strong sales and brand images had been developed by Toyota, Nissan, Honda, Volkswagen, Mercedes-Benz, Audi, Volvo, Saab, and several other firms. Many of the new competing products were targeted towards the market segments that GM had identified in the 1920's. First the Japanese, and more recently the Koreans, have targeted the Chevrolet economy segment. European imports are strongly appealing to the Cadillac status segment. With the addition of new product offerings to the total market, perceived differences in GM lines become smaller.

\section{Reduction in the Available Market Positions}

Second, the influx of competitors, primarily at the high and low ends of the market, has caused a decrease in the relative market space of GM products. The impact of more products on the market is compounded when one examines the markets that have been segmented effectively by imports. The low-end economy market has been dominated by the Japanese, and more recently by Korean and Eastern European manufacturers. The higher end of the market has been dominated by the European imports, and Japanese firms increasingly are targeting this market segment. Such competition has made it necessary for General Motors and other American manufacturers to compete in a more limited area of the market. They have concentrated on the middle of the market because of the similarity among their product lines, and this emphasis may be considered to be one of the major strategic errors in this episode.

It is well documented that General Motors has exhibited a high degree of reluctance to enter the small-car economy end of the market. Concomitantly, due to GM's standardized manufacturing methods, it has been unable to produce distinctive vehicles for the higher end of the market. Most recently this failure has been demonstrated by the poor showing of the Cadillac Allante which was designed to compete with Mercedes-Benz automobiles in the $\$ 50,000$ price range [11]. 


\section{Changing Dernographics}

Finally, changing demographics have heightened the problem of product similarity because those individuals with the greatest brand-perception differences are buying a smaller share of all products as they grow older. Demographics also have reinforced perceptions of product differences. Consider the following scenario, which concerns a buyer of an Oldsmobile in 1965 who was 55 years old. That customer's brand perception probably was based on events which had occurred when that person was 20-25 years old. This would have been in the time period of 1930 to 1935 , just at the time that GM's products were differentiated at their greatest level. Studies have shown that individuals form brand preferences at relatively early ages ([1], pp. 46266 ), some even in childhood [2]. In this case it would be relatively easy 30 years later, in 1965 , to convey substantially different product images with only slight differences in product design cues.

An examination of that hypothetical buyer today reveals a different solution. If that person were alive, he or she would be 77 years old. This person would be retired and normally would be purchasing automobiles much less frequently. The percentage of GM buyers who are retired is growing at a rapid rate; of even greater concern is the number of buyers who are deceased. The old sales joke about the funeral industry, "the market is dead," unfortunately applies all too well in this instance.

\section{Product Proliferation}

While its market space was being reduced and its perceived product differences were being diminished, GM exacerbated the problem by putting more products within this limited market space. Its strategy was designed to appeal to all possible markets; however, it resulted in all company divisions trying to cover every segment with products shared by most GM divisions. At the same time, GM reduced somewhat the discernable differences between its products. One must keep in mind that this strategy probably would have worked very well in the 1950 's, under the vastly different market conditions of that period.

\section{Other Factors}

Several other factors compounded the problem for General Motors. Energy concerns created an increased demand for smaller, more fuel-efficient automobiles. GM moved very slowly in reacting to this trend and did not offer viable products for this market segment. Foreign products, in addition to being seen as more economical, also were perceived as having higher quality and overall value. This in turn caused resale prices of foreign cars to be higher, adding to their appeal. The European and Japanese car makers aggressively instituted major advertising and promotion programs which pointed this out to the consumer.

\section{The "Just Noticeable Difference" Concept}

The problem of GM products that appear to consumers to be similar can be understood further through the concept of "just noticeable difference" ([1], pp 14142). Just noticeable difference, or j.n.d., is based on Weber's Law which was developed 
by two German physiologists in the nineteenth century [3]. This concept states that the stronger the initial stimulus, the greater the change must be in another stimulus to be perceived as different. The basic premise of this concept is that an additional level of stimuli is necessary for most people to see a difference between the new stimulus and the previous one [4]. The degree of stimuli required for a difference to be noticed is a constant ratio of the new stimulus to the initial one.

One example of this concept is a price change. Let's assume a small item, priced at $\$ 3.00$ has a price increase of 22 cents. This amount might fall below the j.n.d. and thus not be noticed by the consumer. An increase of 27 cents might be noticed and cause a decrease in demand. The firm involved would be wise to increase price by the lower amount. The j.n.d. concept holds that the relationship between the differences in stimuli is a constant ratio. Therefore, based on consumer perception in the previous example, an item that had a price of $\$ 30.00$ could be increased by $\$ 2.20$ without a difference in perception by the consumer, yet an increase of $\$ 2.70$ would be noticed.

The just noticeable difference notion is expressed as

$$
\frac{\Delta I}{I}=k
$$

where: $\Delta I=$ the just noticeable difference required to produce a change in perception;

$I=$ the initial stimulus;

$k=$ the constant amount for the stimulus to be noticed.

In pracicice, this concept is valuable to determine price levels, product differences, package sizes, and other elements of marketing strategy. The level of change, or $k$, can be determined through market research using the constant stimuli method until the j.n.d. is reached [4]. In some cases, such as pricing, the object is to find the highest level attainable just below the j.n.d. In other actions such as differentiating products, the object is to determine the level at which a change will be noticeable. This point at which change is noted is referred to as the differential threshold ([10], p. 283).

The change in product perceptions can be seen more clearly by using this concept. The type of product differences required in the past to make products appear different from each other and the competition can be seen as

$$
\Delta I=k(I)
$$

where: $I=$ a positive function of $n, c$, and $1 / p$;

$n=$ the number of products in the market;

$c=$ the differences perceived between competing products;

$p=$ the differences perceived between our products

Both $c$ and $p$ are a function of external stimuli and previously internalized brand perceptions. 
In this case, $\Delta I$ is the degree of product difference required to differentiate GM products from one another and from competitors. $I$ is the initial stimulus, or the consumer's overall perception of products in the marketplace which a new product must be substantially different from. This is a function of the number of products in the marketplace, $n$; the perceived differences between competing products, $c$; and the perceived difference the subject firm's products, $p$. Since $I$ is inversely related to $p$, the function is negative and is expressed $1 / p$. Both sets of product perceptions, $c$ and $p$, are based on external stimuli such as observation of the product, advertising, and word-of-mouth communications. They also are related to previously learned brand identities that reinforce product differences.

What can happen? As the number of products, $n$, increase in the market, the base level of initial stimuli increases, which in turn causes $\Delta I$, the amount required for the new stimulus to be noticed to be increased to maintain the constant change or threshold level, $k$. The differences in product perceptions, $c$ and $p$, likewise impact $I$. As competing product differences within the consumer's base of experience increase, the level of $I$ increases which again in turn requires $\Delta I$ to be greater to maintain a constant $k$. Increases in product differences for the subject firm's products reduce the level of $I$. Expressed another way, this relationship can be seen as

$$
\begin{aligned}
\Delta I & =k(I) \\
& \text { or } \\
\Delta I & =k(n+c+1 / p) .
\end{aligned}
$$

Through the use of this framework, the General Motors experience can be seen as follows. First, the level of product differences, $\Delta I$, that was historically implemented was at or above the level necessary considering the base of experience, $I$, to produce a perception of different products. This was at the historical levels of $n, c$, and $p$. As has been discussed, several changes occurred in the market. The level of $n$, or the number of products in the marketplace, increased with the great increase in the number of foreign competitors. The perceived differences between competing products, $c$, became larger as these products established strong brand identities. Finally, the perceived differences between GM's products, $p$, decreased on average as the population has moved further from the time period where major differences existed between the products.

Based on equation (3) all of these factors would result in an increase in $\Delta I$, or the perceived differences that would have to be created between the General Motors products in order to maintain the constant relationship, $k$, between their products and competing ones. Did this occur? As seen in the previous discussion it did not, and most critics believe that those product differences were actually decreased in recent years. 


\section{What Can Be Learned?}

Several lessons can be learned from the GM experience. First, brand perceptions are based on product positioning and image strategies that take place over a number of years. This product image can disappear quickly if new customers are not developed with similar brand perceptions. The result of such a change can impact even the largest and seemingly most secure firms in the marketplace [14]. This process happened in reverse with Coca-Cola when it attempted to pull from the market a product with long-standing brand identity.

Second, the degree of difference between brand images can change based on new product entrants and the relative product space in which a firm competes. The number of entrants alone can change the differences that may have to be emphasized in order that the desired level of perceptual difference between products can be maintained. The position that products occupy in the marketplace also plays a part in this process; this position can be compressed to a point where perceived product differences are extremely difficult to maintain.

Firms which can accurately measure and implement the just noticeable difference strategy can create a proper degree of difference in their products to make them recognizable and successful in the marketplace. For example, Ford Motor Company's recent success with the Taurus/Sable line is due in large part to the products' distinctive styling which makes them clearly different from their competition and from one another. A degree of risk is associated with this strategy, of course. Products which are seen as being too different or distinct might fail for that reason alone.

Although the automobile industry was used to illustrate the just noticeable difference strategy in this paper, this concept can be applied to virtually any product or service area. It also can be applied to product differentiation as well as market segmentation strategies. For example, the hotel and airline industries are plagued with the problem of consumers not perceiving differences between competitors. In this case, j.n.d. could be applied to the problem of product differentiation, enabling these firms to identify the key dimensions and levels of stimuli to make their products or services appear substantially different than the competition.

The process of implementing j.n.d. is not a particularly difficult one. The correct levels of differences between a firm's products can be readily determined using relatively routine market research procedures. First, a firm would need to ascertain, through a focus group process, the factors and attributes that consumers use to differentiate products. The factors that influence consumers usually span the marketing mix and are not limited to product content alone. For example, customers might inform the moderator that location and atmosphere of stores selling different products are factors that have a major impact on their perceptions. Positive attributes associated with these factors might be comfort, soft textures, and earth-tone colors.

The second step in this procedure is to test, using a concept test of an advertisement pre-test format, increasingly greater levels of differences in the attributes that were seen to be important by consumers. Questionnaires then can measure levels of perceptions of attributes associated with that factor, including direct references to a 
prior stimulus. Once the differential threshold is determined, it can then be utilized in the constant ratio format to define differential thresholds in related areas. Complicating this procedure somewhat are the number of target markets tested, and the number of factors and attributes examined.

This process can be a proactive one where the correct decisions can be made before the product is introduced to the marketplace. Otherwise, corrective actions nust be made after the problem is fully developed. GM, which provided the background lor the illustration of this concept, has started to take actions to reorganize the company in accordance with the original segmentation strategy of the 1920's. Unfortunately, this reorganization has been a slow process [19]. GM also is working on establishing a higher level of product differentiation. Both of these tasks will take years to complete fully and will cost hundreds of millions of dollars. Hopefully the lessons of this experience will not be lost on firms that have currently high sules and orand preierences based on past marketing efforts.

\section{References}

1. Assael, H. Consumer Behavior and Marketing Action, third edition. Boston, MA: Kent Publishing Co. (1987).

2. Bahn, K. D. "How and When do Brand Perceptions and Preferences First Form? A Cognitive Developmental Investigation." Journal of Consumer Research, Vol. 13 (December 1986), pp. 382-93.

3. Britt, S. "How Weber's Law Can Be Applied to Marketing." Busıness Horizons (February 1975), pp. 21-29.

4. Britt, S. "The Marketing Importance of Just Noticeable Difference." Business Horizons (August 1976), pp. 38-40.

5. Bush, J. W. "Buick: Charting a Comeback Tied to Its Roots." Ward's Auto World, Vol. 23 (February 1987), p. 28.

6. Callahan, J. "Cost Cutting, Confusion Plagues GM." Automobile Industry, Vol. 166 (August 1986), p. 27.

7. Callahan, J. M. "Losh Guides Pontiac to New Heights." Automotive Industry, Vol. 166 (August 1986), p. 22.

8. "Can GM Solve Its Identity Crisis?" Business Week (January 23, 1984), pp. 3233.

9. Crabb, R. Birth of a Giant. Philidelphia, PA: Chilton Book Co. (1969).

10. Engel, J. F. and R. D. Blackwell. Consumer Behavior. Hinsdale, IL: Dryden Press (1982), p. 56. 
11. Flint, J. "Allante: Slow Off the Mark." Forbes (November 30, 1987), p. 204.

12. GM: The First 75 Years of Transportation Products. Princeton, NJ: Princeton Institute for Historic Research, 1983 General Motors Corporation, p. 16.

13. Jeriski, L. "Fiddling With Figures While Sales Drop." Forbes (August 24, 1987), pp. 32-35.

14. Krebs, M. "GM Products to Die If They Can't Compete." Automotive News (March 30, 1987), p. 56.

15. Lapham, E. "Olds Places a New Emphasis On Quality to Push its Duds: Delta 88 and Toronado." Automotive News (September 22, 1986), p. 30.

16. Lowell, J. "Cadillac: Selling a Balance Between Status, Performance." Ward's Auto World, Vol. 23 (February 1987), pp. 45-46.

17. Rae, J. B. Nissan/Datsun, A History of Nissan Motor Corporation in the U.S.A. New York, NY: McGraw-Hill (1982).

18. Serafin, R. "Heartbeat: New Ads Pump Life Into Chevy's American Image." Advertising Age, Vol. 28 (January 12, 1987), p. 3.

19. Serafin, R. and P. Strnad. "GM Gets Competitive, Will Drop 39 Models." Advertising Age, Vol. 57 (August 4, 1986), p. 10.

20. Smith, W. R. "Product Diferentiation and Market Segmentation as Alternative Marketing Strategies." Journal of Marketing (July 1956), pp. 3-8.

21. Strnad, P. "New Chevies Lead GM Deproliferation." Advertising Age, Vol. 58 (January 12, 1987), p. 60.

22. Watkins, J. A. The 100 Greatest Advertisements. New York, NY: Dover Publications, Inc. (1959).

23. Zois, D. "GM Strives for Variety in Styling." Automotive News (July 21, 1986), p. 1 . 